Article

\title{
Predictors of Self-Reported Growth Following Religious and Spiritual Struggles: Exploring the Role of Wholeness
}

\author{
Allison C. Hart ${ }^{1}$, Kenneth I. Pargament ${ }^{1, * \mathbb{D}}$, Joshua B. Grubbs ${ }^{1}$, Julie J. Exline ${ }^{2} \mathbb{D}$ and \\ Joshua A. Wilt ${ }^{2}$ (D) \\ 1 Department of Psychology, Bowling Green State University, Bowling Green, OH 43403, USA; \\ allisonhart315@gmail.com (A.C.H.); grubbsj@bgsu.edu (J.B.G.) \\ 2 Department of Psychological Sciences, Case Western Reserve University, Cleveland, OH 44106, USA; \\ julie.exline@case.edu (J.J.E.); joshua.wilt@case.edu (J.A.W.) \\ * Correspondence: kpargam@bgsu.edu
}

Received: 30 June 2020; Accepted: 27 August 2020; Published: 30 August 2020

\begin{abstract}
Religious and spiritual (r/s) struggles have been robustly linked to negative outcomes, such as greater psychological distress, reduced well-being, and difficulty finding meaning in life. $\mathrm{R} / \mathrm{s}$ struggles, however, do not inevitably lead to decline. Many people report post-traumatic and spiritual growth through their r/s struggles, even though correlational studies linking r/s struggles to perceptions of growth have produced mixed results. How do we make sense of this overall pattern of findings? Perhaps growth following $\mathrm{r} / \mathrm{s}$ struggles occurs under certain conditions. Prior conceptual work by Pargament suggests that specific aspects of one's orienting system (i.e., the confluence of $\mathrm{r} / \mathrm{s}$, dispositional, and psychosocial factors which help guide people in their search for significance and purpose) may play a pivotal role in predicting growth or decline in the wake of an r/s struggle. In the present empirical study, we expected to find that among $\mathrm{r} / \mathrm{s}$ strugglers, those with orienting systems marked by greater wholeness would be more likely to report growth and less decline. Four dimensions of greater wholeness (purposiveness, breadth and depth, life affirmation, cohesiveness) were measured by the presence of meaning in one's life, self-control, universality, optimism, compassion, openness to change while tolerating doubt, and a collaborative problem-solving relationship with God. We tested these hypotheses using data from a cross-sectional study $(\mathrm{N}=1162)$ of undergraduates at three universities. Results generally supported our hypotheses, with a few exceptions. Greater wholeness was associated with reports of more growth and less decline after an r/s struggle.
\end{abstract}

Keywords: religion; spirituality; struggles; growth; wholeness

\section{Introduction}

In recent years, investigators have turned their attention to a potentially problematic domain of religious and spiritual life- $\mathrm{r} / \mathrm{s}$ struggles. R/s struggles have been defined as tensions, strains, and conflicts about sacred matters (Exline 2013; Pargament et al. 2005). There are robust links between $\mathrm{r} / \mathrm{s}$ struggles and distress, poorer mental health and well-being across diverse samples, religious groups, and situations (e.g., Abu-Raiya et al. 2015; Exline 2013; Pargament and Exline Forthcoming a; Pargament and Exline Forthcoming b). Similar findings have been reported by researchers working with related constructs, including religious crisis (Piedmont 2020), negative religious coping (Pargament et al. 1998), religious strain (Exline et al. 2000), spiritual distress (King et al. 2017), and spiritual dryness (Bussing et al. 2013).

Although the links between $\mathrm{r} / \mathrm{s}$ struggles and negative outcomes are well established, it is still unclear whether $\mathrm{r} / \mathrm{s}$ struggles inevitably lead to decline. There are a few reasons to suggest this may 
not be the full story. First, the magnitudes of these effects range from modest to moderate, suggesting that many people do not necessarily encounter distress in their experiences of $r / s$ struggles (e.g., Abu-Raiya et al. 2015; Exline et al. 2014a). Perhaps, then, r/s struggles lead to other outcomes among some individuals.

Second, stories of growth through $\mathrm{r} / \mathrm{s}$ struggle are commonplace in the sacred texts of the world's great religions. Religious exemplars including Moses, Buddha, Muhammad, and Jesus all took what Campbell (2008) described as "the hero's journey," in which they were called to leave their ordinary lives, faced a period of testing by struggling with internal or external forces, and returned to their homes transformed into world redeemers. These classic religious stories are supplemented by modern day accounts of people describing personal growth through their $\mathrm{r} / \mathrm{s}$ struggles. For example, after undergoing her own r/s struggle, Chittister (2003) was able to find growth and meaningful transformation. She writes: "The spirituality of struggle is ... a spirituality that takes change and turns it into conversion, takes isolation and makes it independence, takes darkness and forms it into faith, takes the one step beyond fear to courage, takes powerlessness and reclaims it as surrender, takes vulnerability and draws out of it the freedom that comes with self-acceptance, faces the exhaustion and comes to value endurance for its own sake, touches the scars and knows them to be transformational" (p. 96). Her experience is marked by significant growth-oriented shifts in her perspective during $\mathrm{r} / \mathrm{s}$ struggles.

Third, theorists have posited that struggles can be an important source of development and growth in a variety of domains, including the religious and spiritual realm. For example, according to life span psychologist Erikson (1998) theory, every phase of life is accompanied by a distinctive set of crises and developmental tasks. Personality and character are shaped by the way an individual struggles and comes to terms with these challenges. Paralleling Erikson's stage theory, Fowler (1981) has described faith in terms of a series of developmental stages triggered by new environmental demands and challenges that call for new ways of understanding and acting in the world. Although Fowler's articulation of these stages has not gone without criticism, the notion of growth in the religious realm through challenge and transition is widely accepted in the field (Hood et al. 2018). Fowler (1981) writes: "Growth and development in faith also result from life crises, challenges, and the kinds of disruptions that theologians call revelation" (p. 100). These disruptions, Fowler asserts, can lead toward a faith of greater reflectiveness, depth, and universality.

What does the research have to say regarding the connection between $\mathrm{r} / \mathrm{s}$ struggles and reports of personal growth? Self-reported growth has been defined and measured by Tedeschi and Calhoun (1996) as perceptions of positive changes following stressful life experiences that move the person to a higher level of functioning. These changes may involve the discovery of new possibilities for oneself, greater closeness with other people, deeper appreciation for life, the development of more personal strengths, and a deeper spirituality. When asked directly whether they have grown through their $\mathrm{r} / \mathrm{s}$ struggles, many people indicate that indeed they have. For example, $49 \%$ of college students said that they had grown through their r/s struggles (Desai and Pargament 2015). Similarly, 52\% of military veterans moderately or strongly agreed with the item "I have grown spiritually" as a result of their r/s struggles (Teng et al. 2016).

However, correlational studies on the relationship between $\mathrm{r} / \mathrm{s}$ struggles and self-reported growth have yielded mixed results. R/s struggles were associated with more reports of growth in several contexts, including college students dealing with the 9/11 terrorist attacks (Huang et al. 2011), adults living close to the site of the Oklahoma City bombing (Pargament et al. 1998), and survivors of drought in Botswana (Zeligman et al. 2020). Other studies, however, have yielded null findings or, in some instances, negative ties between r/s struggles and self-reported growth (e.g., Chan and Rhodes 2013; Park et al. 2017; Tarakeshwar and Pargament 2001).

In sum, the literature indicates that many people experience distress and mental health problems in relation to $\mathrm{r} /$ struggles, but not all do. Further, classic religious literature, narrative accounts, and psychological theory clearly point to the potential for growth through $\mathrm{r} / \mathrm{s}$ struggles. Surveys also show 
that many people report growth as a result of their $\mathrm{r} / \mathrm{s}$ struggles, even though correlational studies on the links between $\mathrm{r} / \mathrm{s}$ struggle and perceptions of growth have produced mixed results. How do we make sense of this overall pattern of findings? At the very least, these findings suggest that decline is not inevitable after experiencing $\mathrm{r} / \mathrm{s}$ tension and conflict.

A more nuanced explanation may be needed to understand this literature and the implications of $\mathrm{r} / \mathrm{s}$ struggles for self-reported growth. Perhaps people who struggle with $\mathrm{r} / \mathrm{s}$ can grow, but only under certain conditions. In his model of spirituality, Pargament (2007) proposed that the trajectory of $\mathrm{r} / \mathrm{s}$ struggles will be determined, in part, by characteristics of the individual's orienting system. The orienting system refers to stable values, beliefs, practices, and relationships that guide the individual toward the realization of significant purposes in life.

As we will see, several studies have shown promise in identifying some of the orienting system variables that may contribute to perceptions of growth in relation to r/s struggles. Further advances, however, likely depend on a clearer conceptual framework for distinguishing between orienting systems that are likely to foster reports of growth from those that are not. Wholeness is one overarching feature of the orienting system that may have important implications for the extent to which people reportedly experience growth in the wake of $\mathrm{r} / \mathrm{s}$ struggles.

\section{Wholeness and Growth}

Writing earlier about the relative effectiveness of different orienting systems, Pargament (2007) distinguished among orienting systems in terms of the degree to which they are well-integrated. More recently, he and his colleagues, have used the terms "wholeness" and "brokenness" to describe well-integrated and poorly integrated orienting systems (Pargament and Exline Forthcoming b; Pargament et al. 2016; Pargament et al. forthcoming). Wholeness, as they define it, has to do with how well people put the bits and pieces of their lives together. Generally, wholeness has not received a great deal of psychological attention as an important aspect of well-being, with a few notable exceptions. James (1902), for example, maintained that central to human functioning at its best was the unification of the divided self-the material self, the social self, the spiritual self, and pure Ego. Similarly, Kurtz and Ketcham (1992) noted that people are motivated to seek out a larger wholeness in spite of the fact that perfection is never fully attainable: "For to be human," they write, "is to be incomplete, yet yearn for completion; it is to be uncertain, yet long for certainty; to be imperfect, yet long for perfection; to be broken, yet crave wholeness" (p. 19).

Several qualities of wholeness are of note (Pargament et al. forthcoming). First, wholeness does not refer to any single attribute. For example, it goes beyond the simple perception of being whole. Rather, it involves the constellation of thoughts, emotions, actions, relationships, motivations, and experiences that define a person. Wholeness does not address an individual in isolation; instead, it speaks to the person in relation to a larger social and situational context. Second, wholeness is a dynamic process of movement toward a higher-order organization that continuously evolves over the lifespan. However, wholeness can never be completely attained because life never fails to present new challenges and because people are limited beings. Thus, it is more accurate to speak of people in terms of their degrees of wholeness. Third, wholeness is a capacity. Although some writers assert that people contain an inner wholeness that can be released or freed from constraints (e.g., Palmer 2004), we would say instead that people have a potential or capacity for wholeness that can be fostered to a greater or lesser degree. Fourth, wholeness and brokenness are not antithetical to each other. Few, if anyone, goes through life without suffering wounds and experiencing some degree of brokenness. Wholeness, then, is not the elimination of brokenness but involves ways to incorporate brokenness into the life journey (Russo-Netzer 2018). This point is illustrated by kintsugi, a centuries-old Japanese art form. In kintsugi, a ceramic is broken into shards and then pieced together with gold or silver filigree. By making visible the brokenness of the ceramic, the beauty of the newly whole object is enhanced. Finally, there is an affinity between wholeness and holiness. In fact, the term holiness is rooted in the Old English word halig, meaning wholeness, health, and happiness (New World Encyclopedia 2008). 
Fostering wholeness and holiness are central religious tasks, according to classic theorists. For example, Allport (1950) spoke of religion in its mature form as a "uniquely integral system" that attempts to organize all of life into a meaningful whole (p. 124). Religion and spirituality, at their best, then, may contribute an overarching organization to all of the elements of life, including $\mathrm{r} / \mathrm{s}$ struggles.

Several dimensions of wholeness have been delineated by Pargament and his colleagues (Pargament et al. 2016; Pargament et al. forthcoming). In this paper, we focus on four of these dimensions-purposiveness, breadth and depth, life affirmation, and cohesiveness-and their implications for $\mathrm{r} / \mathrm{s}$ struggle-related growth.

\subsection{Purposiveness}

"Starting fairly early in our lives," Allport (1950) once wrote, "we are propelled ... not by instincts, but interests" (p. 155). Similarly, Frankl (1959) maintained that the discovery and realization of a higher purpose or meaning is perhaps the key task for living. The pursuit of a purpose in life and the sense of meaning that pursuit offers represent an important ingredient of wholeness. Purposiveness lends stability, direction, and organization to the search for significance. Moreover, purposiveness provides the grounding confidence that one's life truly matters. Confidence in the meaning and worth of one's life may be especially valuable when individuals encounter struggles. Consider, for example, the purposiveness embedded in the words of 13-year-old Frank (2010) written while hiding with her family from the Nazis in a Dutch attic: "I know what I want, I have a goal, an opinion, I have a religion and love. Let me be myself and then I am satisfied" (p. 214). In spite of the tremendous adversity she faced, she never lost sight of what she valued and the hope in the fulfillment that it would provide her.

A few studies provide some support for the value of meaning and purposiveness when people face $\mathrm{r} / \mathrm{s}$ struggles. Working with a large sample of college students who were experiencing $\mathrm{r} / \mathrm{s}$ struggles, Wilt et al. (2016) reported that those who saw meaning in their struggles reported greater life satisfaction and self-esteem, and lower depression and anxiety. In another study of college students who experienced r/s struggles, Desai and Pargament (2015) also found that reports of secular growth, spiritual growth, and less spiritual decline were generally linked to greater meaning found in the struggle. Further, military veterans who endorsed higher levels of meaning while dealing with an $\mathrm{r} / \mathrm{s}$ struggle also reported greater spiritual growth, less spiritual decline, and better adjustment to the struggle (Wilt et al. 2019b).

\subsection{Breadth and Depth}

Wholeness calls for a broad orienting system that equips individuals with an extensive set of resources to deal with the diverse and often complicated array of thoughts, practices, emotions, people, and challenges (including $\mathrm{r} / \mathrm{s}$ struggles) that will be encountered over the lifespan. Wholeness also requires the ability to see beneath surface appearances and reflect on oneself, people, and problems more deeply. Those familiar with a variety of tools and resources and who can delve deeply into the complexities of life are in a better position to gain from their struggles. One illustration of this point comes from a study of Polish Roman Catholic women showing that a range of coping skills, such as planning and active problem-solving, mediated the relationship between spiritual struggles and life satisfaction (Szcześniak et al. 2020).

Religion and spirituality are particularly concerned about matters of breadth and depth. They address most of life's great existential questions: How did we get here? Why are we here? How should we treat ourselves and others? Why is there suffering and injustice, and how should we respond to them? How do we handle the conflicts and divisions within ourselves? What happens when we die? The central focus of religion and spirituality is a human being of breadth: an individual and a part of a larger community; someone with a history, present, and future; a being with the potential for good and bad; one who knows, experiences, acts, and relates; and a person who can grapple with suffering and savor life's greatest joys. In this vein, one study of patients with cancer from the Netherlands showed that those with a more "omnipresent spirituality" were able to integrate their experience of 
cancer into the larger story of their lives (Viser et al. 2020). Breadth also incorporates others who come from different backgrounds, religions, and cultures into the human community. It encourages an appreciation for human diversity, in religious and non-religious forms. This appreciation rests on a recognition of our common humanity as well as our fundamental differences in values, world views, and practices (Morgan and Sandage 2016).

Religion and spirituality have to do with the depth as well as the breadth of life. All deal with something more than ordinary material existence and encourage people to view the world through a sacred lens. Through prayer, meditation, ritual, or study, people are taught to see a deeper sacred meaning in seemingly secular aspects of life, such as work, strivings, the body, nature, the arts and humanities, marriage and family, and social change (Pomerleau et al. 2017). Relevant to this point, Kitchens (2015) conducted a series of experimental studies in which some participants were primed to think about God while others were primed to think about other topics, such as friends. In comparison to those in the other priming conditions, participants primed to think about God reported significantly higher levels of internal reflection on their thoughts and feelings.

A few studies suggest that greater religious or spiritual depth and breadth may facilitate well-being and growth in the aftermath of $\mathrm{r} / \mathrm{s}$ struggles. In one investigation of a national sample, higher levels of religious commitment and perceptions of life as sacred buffered the negative effects of $\mathrm{r} / \mathrm{s}$ struggles on unhappiness and depression (Abu-Raiya et al. 2016). In two other studies, higher levels of perceived spiritual and secular growth among $\mathrm{r} / \mathrm{s}$ strugglers were reported by those who were more deeply involved in their religious beliefs and practices (Desai and Pargament 2015; Wilt et al. 2019a). It is important to add the qualification that people can approach religion and spirituality in ways that lack breadth and depth, as in the case of religiously based intolerance towards outgroups that follow a different set of beliefs and practices (e.g., Hall et al. 2010).

\subsection{Life Affirmation}

Wholeness also rests on an affirming orientation to life (cf., Doehring 2015), one marked by compassion for oneself and others. This sense of compassion may be an important resource in the face of r/s struggles. In this regard, Zarzycka and Puchalska-Wasyl (2019) conducted a study with Polish college students that showed that the effects of $r / s$ struggles (and intrapersonal struggles in particular) on psychological well-being were mediated in part by self-supporting internal dialogues. Life affirmation also involves positive expectations for the future. An affirming orientation does not deny the reality of pain and suffering in the world, but rather insists that darkness does not have the only or final word; there is hope for a better tomorrow even in the midst of struggles.

Religion and spirituality represent important sources of life affirmation, especially in dark times (Vishkin et al. 2016). The world's major religious traditions share the belief that $\mathrm{r} / \mathrm{s}$ struggles can be a pathway to enlightenment, liberation, salvation, or eternal life. Several empirical studies have

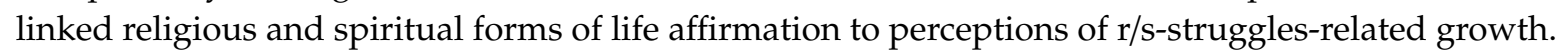
A meta-analysis indicated that positive forms of $r / s$ coping, those that rest on a benevolent view of God and the universe, were one of the strongest predictors of perceived stress-related growth (Prati and Pietrantoni 2009). Among $\mathrm{r} / \mathrm{s}$ strugglers in particular, positive $\mathrm{r} / \mathrm{s}$ coping methods have been linked to self-reported growth in several samples (Desai and Pargament 2015; Exline et al. 2017; Wilt et al. 2019b; Wilt et al. 2019c). For example, Saritoprak et al. (2017) assessed the degree to which $\mathrm{r} / \mathrm{s}$ struggling Muslims and Christians viewed their struggles as a test that will lead them closer to God and a way to become more devout. This outlook, which was labeled "transformational trials" in the Christian sample and "spiritual jihad" in the Muslim sample, was associated with perceived spiritual growth in both groups. Other life-affirming religious and spiritual expressions and experiences have also been tied to reports of growth among those who struggle religiously and spiritually; these factors include religious support (Desai and Pargament 2015), experiences of sacred moments (Wilt et al. 2019a), and perceptions that God has been actively helpful in one's life (Exline et al. 2017; Wilt et al. 2019c). 


\subsection{Cohesiveness}

Like the composer who must assemble musical notes and orchestral instruments into a unified composition, people are faced with the challenge of putting the diverse pieces of life-values, impulses, actions, beliefs, dreams, relations-into a cohesive pattern that can lead toward significant goals, even when faced with turmoil and struggle. Cohesiveness is made up of several qualities. First, it involves the ability to balance competing demands, desires, commitments, and roles. James (1902) spoke to the importance of balance: "Strong affections need a strong will; strong active powers need a strong intellect; strong intellect needs strong sympathies to keep life steady" (p. 333). For example, within the religious and spiritual realm, many people try to reconcile personal responsibility for their own problems with beliefs in God's control in life (Pargament et al. 1988). On one hand, some take a self-directed approach to problem solving that relies exclusively on personal initiative. On the other, some defer all responsibility for solving problems to God, relying exclusively on divine action. Most commonly, however, people find a balance between personal and divine control by perceiving a collaborative problem-solving partnership with God.

Second, cohesiveness calls for the wisdom and discernment to know when to do what: when to work independently and when to seek out support, when to take direct action and when to retreat or gracefully surrender, when to make minor adjustments and when to make a major life transformation. This is the kind of discernment embodied in the Niebuhr's Serenity Prayer: "God, grant me the serenity to accept the things I cannot change, Courage to change the things I can, and wisdom to know the difference." Wisdom represents a higher order form of mastery, what Baltes and Staudinger (2000) described as a heuristic that "organizes and orchestrates knowledge toward human excellence in mind and virtue" (p. 122).

Third, cohesiveness requires a willingness to ask questions, an openness to change, and the flexibility to adapt. Openness to change may be especially important if people are to grow through their $\mathrm{r} / \mathrm{s}$ struggles because these times of turmoil may signal the need for reorientation and perhaps re-evaluation of what is significant. In this vein, Calhoun et al. (2000) examined the relationship between a quest orientation and growth following trauma. Quest represents a flexible approach to religious and spiritual issues, one that values the process of questioning and change (Batson et al. 1993). Among college students who had experienced a traumatic event, those who scored higher on the openness to change subscale of the quest measure manifested higher levels of post-traumatic growth.

Finally, cohesiveness involves an ability to accept and live with life's paradoxes and struggles. This ability is highlighted within Fowler (1981) penultimate stage of faith maturity, "Conjunctive Faith." This stage recognizes that the truths we hold are partial and incomplete. It is, in the words of Fowler, "alive to paradox and the truth in apparent contradictions" (p. 198). Rockenbach et al. (2012) examined the $\mathrm{r} / \mathrm{s}$ struggles of college students using qualitative methods and found that their stories of struggle were "steeped in the conflicting, contradictory, and paradoxical aspects of life" (p. 62). Growth, they found, involved continuing efforts to reconcile the tensions between ideal and actual selves, between revealed and concealed selves, between self and others, and between one's world view and lived realities.

\section{The Present Study}

We have suggested that reports of growth may occur among $\mathrm{r} / \mathrm{s}$ strugglers, but only under certain conditions. This may explain the mixed findings in the literature on this topic. One important determinant of whether people who encounter $\mathrm{r} / \mathrm{s}$ struggles experience growth may be the degree to which the individual is whole. People with orienting systems that are more whole may be better able to use their $\mathrm{r} / \mathrm{s}$ struggles as a launching pad for positive change and transformation. Initial research provides some support for this notion. Much of this research has focused on religious and spiritual predictors of growth. The findings make the somewhat paradoxical point that religion and spirituality may be both a potential problem as well as offer a potential solution to that problem. 
Drawing on the conceptual work on wholeness, the present study explored a wider array of possible predictors of self-reported growth in the wake of $\mathrm{r} / \mathrm{s}$ struggles. We selected several indicators that represent the four dimensions of wholeness: purposiveness, breadth and depth, life affirmation, and cohesiveness. These indicators are by no means the only possible ways to operationalize wholeness, but rather represent what we hope is a solid starting point from which to explore this overarching construct. We then tested whether these indicators were tied to self-reported growth among people experiencing $\mathrm{r} / \mathrm{s}$ struggles. To assess different aspects of growth, we examined three growth-related criteria: post-traumatic growth, spiritual growth, and spiritual decline.

\section{Methods}

\subsection{Participants and Procedure}

This cross-sectional exploratory study was part of a larger study on spiritual struggles in the lives of college students (Exline et al. 2014b). Previous studies have used this data set to examine theological beliefs about suffering (Wilt et al. 2017a), trajectories of r/s struggles (Wilt et al. 2017b), and predictors of $\mathrm{r} / \mathrm{s}$ struggle (Stauner et al. 2019). The present study examines the relationships among several individual and interpersonal religious, spiritual, and secular factors and various outcomes for individuals who have encountered $\mathrm{r} / \mathrm{s}$ struggles. Undergraduate students enrolled in introductory psychology courses were drawn from three college campuses in the U.S, one private and one public university in the Midwest and a religiously affiliated university in the Western U.S. Of an initial group of 4006 students who were screened, the sample of this study consisted of 1162 respondents ( $99 \%$ were 23 years and younger, $73.3 \%$ Caucasian, and $69.2 \%$ female) from Time 1 of the study. In this sample, the participants identified with the following religious affiliations: Catholic (13.4\%), Protestant (19.6\%), Christian (unspecified or other, 36.5\%), Jewish (0.7\%), Muslim (0.3\%), Hindu (0.5\%), Buddhist $(0.3 \%)$, Agnostic or unsure $(4.1 \%)$, None $(2.9 \%)$, and Atheist $(1.3 \%)$. Atheists were included in the study because empirical study indicates they too can report $\mathrm{r} / \mathrm{s}$ struggles and their struggles are also associated with psychological adjustment (Sedlar et al. 2018). Participants endorsed engaging in the following activities at least once in the last week: prayed or meditated (86.5\%) and attended a religious or spiritual service or meeting $(67.5 \%)$.

All participants were given partial credit in their introductory psychology courses for completing the web-based survey titled "Personality, Beliefs, and Behaviors." For this study, the inclusion criterion was a participant's endorsement of experiencing an $\mathrm{r} / \mathrm{s}$ struggle over the past several months. This was captured in two ways: First, participants responded to a 9-item questionnaire measuring six domains of r/s struggles: divine, demonic, interpersonal, moral, doubt, and ultimate meaning. They rated each item on a Likert-type scale ranging from 1 (not at all/does not apply) to 5 (extremely), with higher scores indicating a greater level of $\mathrm{r} / \mathrm{s}$ struggles. Participants who indicated some degree of an $\mathrm{r} / \mathrm{s}$ struggle on any struggle, from 2 (a little bit) through 5 (extremely), were included in the study. Example items include: "Over the past several months, have you had any of these experiences" ... "doubts or questions about $\mathrm{r} / \mathrm{s}$ (including doubts about specific $\mathrm{r} / \mathrm{s}$ beliefs);" "negative thoughts or feelings focused on God or the idea of God (e.g., anger, mistrust, fear, unloved);" "feelings of anger, hurt, mistrust ... focused on religious people or religion in general;" "doubt about whether your life has any deeper spiritual meaning or purpose;" "feeling attacked by the devil or evil spirits." Second, participants were included in the study if they responded "yes" to a question asking if they had experienced an $\mathrm{r} / \mathrm{s}$ struggle not listed in the 9-item measure. With respect to the nine screening items, the modal response of participants to the degree of struggle they had experienced was "a little bit." For example, in response to the screening item about their degree of struggle with negative thoughts or feelings focused on God, $54 \%$ indicated "a little bit," 28\% "moderately," 13\% "quite a bit," and 5\% "extremely." Although the degree of struggle was positively skewed in the sample that was screened into the study, studies of $\mathrm{r} / \mathrm{s}$ struggle consistently report that participants tend to show relatively low levels or intensities of r/s struggle on average (e.g., Abu-Raiya et al. 2015; Exline et al. 2014b). Nevertheless, 
in spite of their positive skewness, $r$ /s struggles are robust predictors of psychological distress and poorer mental health. Thus, even low levels of $\mathrm{r} / \mathrm{s}$ struggles can have significant implications for mental health. It is important to add here that only $6.1 \%$ of the sample indicated that their r/s struggle had been "totally resolved." The majority of the participants then were continuing to experience a struggle that was to some degree unresolved.

\subsection{Measures}

We selected two predictor measures per each of the four dimensions of wholeness (eight total). Because wholeness has not received direct research attention, we chose measures based on purely conceptual grounds. Admittedly, these measures do not necessarily assess wholeness in all of its richness and complexity. They are simply a starting point for examining the ingredients that contribute to wholeness in a person's orientation to life. Table 1 in the results section presents these variables along with their reliabilities, means, standard deviations, and ranges.

Table 1. Descriptive Statistics on all Primary Variables.

\begin{tabular}{cccc}
\hline Variables & Mean (sd) & Range & Cronbach's Alpha \\
\hline Presence of Meaning & $4.9(1.4)$ & $1-7$ & 0.91 \\
Self-Control & $3.1(0.54)$ & $1-5$ & 0.75 \\
Religious Participation & $3.2(1.3)$ & $1-6$ & 0.90 \\
Universality & $3.2(2.1)$ & $1-6$ & 0.92 \\
Optimism & $3.5(0.60)$ & $1-5$ & 0.74 \\
Compassion & $5.6(1.2)$ & $1-7$ & 0.90 \\
Collaborative Style & $2.9(1.1)$ & $1-5$ & 0.93 \\
Quest Orientation & $5.5(1.7)$ & $0-10$ & 0.80 \\
Post-Traumatic Growth & $2.5(0.75)$ & $1-4$ & 0.93 \\
Spiritual Growth & $3.9(1.8)$ & $1-7$ & 0.94 \\
Spiritual Decline & $2.8(1.5)$ & $1-7$ & 0.89 \\
\hline
\end{tabular}

\subsubsection{Purposiveness Dimension}

Presence of meaning. To assess the extent to which people experience a sense of purpose in life, we selected the Presence subscale from the Meaning in Life Questionnaire (MLQ, Steger et al. 2006). Respondents rated five items on a Likert-type scale ranging from 1 (absolutely untrue) to 7 (absolutely true), with higher scores indicating a greater endorsement of having a sense of meaning or purpose in one's life. Example items include, "my life has a clear sense of purpose" and "I have a good sense of what makes my life meaningful." Convergent and discriminant validity were found in the initial study, and high internal consistency was found in an independent sample in a later study $(\alpha=0.85$; Steger and Frazier 2005).

Self-control. An individual's ability to persist and endure in the pursuit of significant goals was examined by the Brief Self-Control scale (BSC; Tangney et al. 2004). Six items were rated using a 5-point Likert-type scale, ranging from 1 (not at all like me) to 5 (very much like me), with higher scores indicative of greater self-control. Example items include, "I am able to work effectively toward long-term goals," and "I am good at resisting temptation." High test-retest reliability $(\alpha=0.87)$ and internal consistency $(\alpha=0.85)$ were found in the original study.

\subsubsection{Breadth and Depth Dimension}

Religious Participation. The degree to which the individual is extensively and intensively involved in a religious or spiritual life was assessed by a 6-item religious participation scale that measures the depth of involvement in several $\mathrm{r} / \mathrm{s}$ activities, such as prayer, meditation, reading sacred texts, talking to others about r/s, or attending r/s programs (Exline et al. 2000). Respondents rated these six items on a Likert-type scale ranging from 1 (not at all) to 6 (more than once per day), with higher scores indicating 
greater weekly $\mathrm{r} / \mathrm{s}$ participation. Higher internal consistency $(\alpha=0.91)$ was found in the original study that contained the full scale with 17 items, and in the present study that shortened the scale $(\alpha=90)$.

Universality. The degree to which individuals have an open and accepting attitude toward all religions as a valid way of seeking God/Truth was measured by the Universality subscale from the Multidimensional Quest Orientation Scale (MQOS; Beck and Jessup 2004). This measure does not assess the view that there is a commonality in religious beliefs and practices across faiths, but rather an appreciation for the diversity among religions and their common spiritual yearning and humanity. Respondents rated four items on a Likert-type scale ranging from 1 (disagree strongly) to 7 (agree strongly), with higher scores indicating greater universality. Sample items include, "I think major world religions are equally valid ways to seek God," and "the major world religions may take different paths, but each path ultimately leads to God." The original study found high internal consistency $(\alpha=0.87)$ for the universality subscale.

\subsubsection{Life Affirmation Dimension}

Optimism. The Optimism subscale from the Life Orientation Tests-Revised (LOT-R) and the Extended Life Orientation Test (ELOT) measures were selected to assess the extent to which an individual maintains expectations of positive outcomes or has a positive perspective on life (Chang et al. 1997; Scheier et al. 1994; Scheier and Carver 1992). Halfway through Time 1 of the study, the LOT-R was exchanged for use of the ELOT. Participant responses were merged to create a single optimism variable. Each scale is composed of six items that were rated by respondents on a Likert-type scale from 0 (strongly disagree) to 4 (strongly agree), with higher scores indicating greater levels of optimism. Sample items include, "in uncertain times, I usually expect the best," and "I'm always optimistic about my future." The original studies found acceptable internal consistencies for the LOT-R $(\alpha=0.78)$ and the ELOT $(\alpha=0.77)$.

Compassion. Compassion toward others was measured by the Santa Clara Brief Compassion Scale (SCBCS), which examined the extent to which individuals viewed others with care, concern, and tenderness, and extended support, help and understanding toward another (Hwang et al. 2008). Five items were rated by respondents on a Likert-type scale from 1 (not at all true of me) to 7 (very true of $m e$ ), with higher scores indicating greater levels of compassion toward others. Sample items include, "I tend to feel compassion for people, even though I do not know them," and "one of the activities that provide me with the most meaning to my life is helping others in the world when they need help." The original study found high internal consistency $(\alpha=0.95)$.

\subsubsection{Cohesiveness Dimension}

Collaborative Style. Pargament et al. (1988) developed a useful way of distinguishing less balanced from more balanced approaches to achieve a religious and spiritual sense of control in problem solving. They contrast (a) a Deferring Religious style in which the individual delegates all responsibility for problem solving to God without any personal input, (b) a Self-Directing Religious style in which the individual takes all responsibility for problem solving without any external input from God, with (c) a Collaborative Religious style in which the responsibility for problem solving is shared between the individual and God. In this study, we assessed balance in part by the Collaborative subscale of the Religious Problem-Solving Scales (Pargament et al. 1988). The collaborative style subscale contained six items rated on a Likert-type scale ranging from 1 (never) to 5 (always), with higher scores indicating a greater endorsement of a collaborative problem-solving style. Sample items include, "when considering a difficult situation, God and I work together to think of possible solutions," and "together, God and I put my plans into action." The original study found high internal consistency $(\alpha=0.94)$.

Quest. The 12-item Revised Quest Scale was selected to measure the degree to which participants take a flexible, questioning approach in their religious and spiritual exploration of existential concerns in living (Batson and Schoenrade 1991). This measure contains items which assess a readiness to approach complex $\mathrm{r} / \mathrm{s}$ questions without minimizing their perplexing nature, an openness to change 
in one's r/s beliefs and convictions, and an ability to perceive religious doubt and uncertainties as positive. The 12 items were rated on a Likert-type scale ranging from 0 (strongly disagree) to 10 (strongly agree), with higher scores indicating a greater quest orientation to $\mathrm{r} / \mathrm{s}$. Consistent with general research practice, we focused on the total Quest score in this study. Example items include, "there are many religious/spiritual issues on which my views are still changing," and "questions are far more central to my religious/spiritual experience than are answers." The internal consistency for the original study was acceptable $(\alpha=0.81)$.

\subsubsection{Criterion Measures}

Three criterion measures were used to assess self-reports of post-traumatic growth, spiritual growth, and spiritual decline in the wake of an $\mathrm{r} / \mathrm{s}$ struggle.

Post-Traumatic Growth. A shortened version of the Post-Traumatic Growth Inventory (PTGI; Tedeschi and Calhoun 1996) was used to assess the extent to which individuals reported positive outcomes related to their $\mathrm{r} / \mathrm{s}$ struggle, such as developing greater appreciation for life, increased closeness to others, and personal transformation. Two spiritual items assessing post-traumatic spiritual growth were removed during the scoring process to avoid overlap with the other criteria of spiritual growth and spiritual decline. Respondents rated 11 items on a Likert-type scale ranging from 1 (not experienced) to 4 (a very great degree), with higher scores indicating greater post-traumatic growth. Sample items include, "knowing that I can count on people in times of trouble," and "seeing new opportunities that would not have been available otherwise." High internal consistency was found in the original study $(\alpha=0.90)$.

Spiritual Growth. One abbreviated subscale from the Spiritual Transformation Scale (STS) was selected to assess the extent to which individuals perceived spiritual growth following an $\mathrm{r} / \mathrm{s}$ struggle (Cole et al. 2008). Six items from the 'spiritual growth' subscale were rated by respondents on a Likert-type scale ranging from 1 (not at all true) to 7 (very true), with higher scores indicating greater self-reported spiritual growth. Example items include, "spirituality has become more important to me," and "I spend more time taking care of my spiritual needs." The original study found excellent internal consistency $(\alpha=0.98)$.

Spiritual Decline. To assess the full range of possible spiritual outcomes, one abbreviated subscale from the Spiritual Transformation Scale (STS) was selected to measure the extent to which individuals reported spiritual decline after an $\mathrm{r} / \mathrm{s}$ struggle (Cole et al. 2008). Six items from the spiritual decline subscale were rated by respondents on a Likert scale ranging from 1 (not at all true) to 7 (very true), with higher scores indicating greater spiritual decline. Example items include, "in some ways I have shut down spiritually," and "I am more spiritually wounded." The original study found high internal consistency $(\alpha=0.86)$.

\section{Results}

Means, standards, deviations, and alpha coefficients were calculated for each of the predictor and criterion variables (see Table 1 below). All of the Cronbach's alpha $(\alpha)$ coefficients were in the acceptable range.

Preliminary Pearson correlations were conducted to identify potential relationships between demographic variables (i.e., gender (male/female), ethnicity (non-White/White), age), and criterion measures. Female participants reported more post-traumatic growth $(r=0.09, p=0.001)$ and spiritual growth $(r=0.06, p=0.035)$ than male participants. Participants who did not identify as White also reported more post-traumatic growth $(r=-0.13, p=0.000)$ and spiritual growth $(r=-0.10, p=0.002)$ than those who identified as White. Gender and ethnicity were not significantly related to spiritual decline. Though age was not significantly related to the criteria, we chose to include age as a control variable as is common practice. Therefore, gender, ethnicity, and age were controlled in subsequent regression analyses. Intercorrelations were also conducted among the predictor variables to identify possible multicollinearity issues and none were found to be correlated with one another to this degree 
$(r<0.80$ as specified in Licht 1995). Interestingly and unexpectedly, both the quest and universality scales were significantly negatively correlated with most of the other measures of wholeness, though the two scales were significantly positively related to each other.

Pearson correlations were conducted to examine associations among the predictor and criterion variables (Table 2). With some exceptions, the correlations were generally consistent with our expectations and were small to moderate in nature (Pearson's $r=0.01$ to 0.59 and -0.01 to -0.64 , $p<0.01)$.

In regard to the purposiveness dimension of wholeness, greater presence of meaning in one's life was associated with reports of more post-traumatic growth and spiritual growth, and less spiritual decline. Higher scores on self-control were linked with greater spiritual growth and less spiritual decline. Focusing on the breadth/depth dimension, higher levels of religious and spiritual participation were associated with perceptions of more post-traumatic growth, greater spiritual growth, and less spiritual decline. Unexpectedly, however, greater universality was related to less post-traumatic growth, less spiritual growth, and more spiritual decline. Turning to the cohesive dimension, a more collaborative relationship with God was tied to greater reports of post-traumatic growth and spiritual growth and to less spiritual decline. Findings with respect to the quest orientation to $\mathrm{r} / \mathrm{s}$ were mixed. Greater endorsement of a quest orientation to $\mathrm{r} / \mathrm{s}$ was associated with higher levels of self-reported post-traumatic growth, but also to greater spiritual decline. With respect to the life-affirming dimension of wholeness, greater optimism was correlated with more reported post-traumatic growth and greater spiritual growth, and less spiritual decline. Greater compassion was tied to greater self-reported post-traumatic growth and spiritual growth.

To test the model of wholeness as a predictor of each criterion variable and the independent predictive power of each of the eight wholeness variables, three separate hierarchical regressions were conducted for the three criterion measures (i.e., post-traumatic growth, spiritual growth, spiritual decline). In the first step, the three demographic control variables were entered into the analysis. In the second step, the eight wholeness predictors were entered simultaneously (Table 3 ). In order to control for family wise error rate given the number of multiple comparisons in each regression, the acceptable critical $p$-value was changed from $p \leq 0.05$ to $p \leq 0.005$. The critical $p$-value was calculated using Bonferroni correction methods, whereby the typically acceptable critical $p$-value of $\leq 0.05$ was divided by the number of predictors in each regression (11 per regression). 
Table 2. Intercorrelations among predictor and criterions variables.

\begin{tabular}{|c|c|c|c|c|c|c|c|c|c|c|c|}
\hline Variables & 1 & 2 & 3 & 4 & 5 & 6 & 7 & 8 & 9 & 10 & 11 \\
\hline 1. Presence of Meaning & - & $0.29^{* *}$ & $0.44^{* *}$ & $-0.39 * *$ & $0.45^{* *}$ & $0.25^{* *}$ & $0.40^{* *}$ & $-0.22 * *$ & $0.22 * *$ & $0.34^{* *}$ & $-0.31^{* *}$ \\
\hline 2. Self-Control & & - & $0.19^{* *}$ & $-0.17^{* *}$ & $0.30 * *$ & $0.14^{* *}$ & $0.22 * *$ & $-0.21^{* *}$ & 0.05 & $0.15^{* *}$ & $-0.27^{* *}$ \\
\hline 3. Religious Participation & & & - & $-0.64 * *$ & $0.20 * *$ & $0.19^{* *}$ & 0.52 ** & $-0.11^{* *}$ & $0.29^{* *}$ & $0.56^{* *}$ & -0.20 ** \\
\hline 4. Universality & & & & - & $-0.11^{* *}$ & -0.01 & $-0.31^{* *}$ & $0.30 * *$ & $-0.13^{* *}$ & $-0.34^{* *}$ & $0.17^{* *}$ \\
\hline 5. Optimism & & & & & - & $0.21 * *$ & $0.21^{* *}$ & $-0.13^{* *}$ & $0.18^{* *}$ & $0.21^{* *}$ & $-0.26^{* *}$ \\
\hline 6. Compassion & & & & & & - & $0.23 * *$ & 0.01 & 0.26 ** & $0.27 * *$ & -0.04 \\
\hline 7. Collaborative Style & & & & & & & - & $-0.13^{* *}$ & $0.29^{* *}$ & $0.50^{* *}$ & -0.22 ** \\
\hline 8. Quest Orientation & & & & & & & & - & $0.10^{* *}$ & 0.03 & $0.30 * *$ \\
\hline 9. Post-Traumatic Growth & & & & & & & & & - & $0.59^{* *}$ & 0.02 \\
\hline 10. Spiritual Growth & & & & & & & & & & - & $-0.12^{* *}$ \\
\hline 11. Spiritual Decline & & & & & & & & & & & - \\
\hline
\end{tabular}


Table 3. Multiple Hierarchical Regressions by Criterion Variables.

\begin{tabular}{|c|c|c|c|c|c|}
\hline \multirow{3}{*}{ Predictors } & \multicolumn{5}{|c|}{ Criterion Variable } \\
\hline & \multicolumn{5}{|c|}{ PT Growth } \\
\hline & $\beta$ & B & CI (B) & $p$ & $\mathbf{R}^{2}$ Change \\
\hline Gender & 0.07 & 0.11 & $0.0,0.21$ & 0.049 & \\
\hline Ethnicity & $-0.10 *$ & -0.20 & $-0.33,-0.07$ & 0.003 & \\
\hline \multirow[t]{2}{*}{ Age } & -0.02 & -0.01 & $-0.04,0.02$ & 0.593 & \\
\hline & & & & 0.003 & $0.016 *$ \\
\hline Presence of Meaning & 0.08 & 0.04 & $0,0.08$ & 0.055 & \\
\hline Self-Control & -0.08 & -0.10 & $-0.19,-0.01$ & 0.025 & \\
\hline Rel. Participation & $0.17 *$ & 0.10 & $0.05,0.15$ & 0.000 & \\
\hline Universality & 0.02 & 0.01 & $-0.02,0.04$ & 0.636 & \\
\hline Optimism & 0.10 & 0.07 & $0.02,0.12$ & 0.006 & \\
\hline Compassion & $0.15 *$ & 0.09 & $0.05,0.13$ & 0.000 & \\
\hline Collaborative Style & $0.13 *$ & 0.09 & $0.04,0.14$ & 0.001 & \\
\hline \multirow[t]{4}{*}{ Quest } & $0.15 *$ & 0.02 & $0.01,0.03$ & 0.000 & \\
\hline & & & & 0.000 & $0.15 *$ \\
\hline & \multicolumn{5}{|c|}{$\begin{array}{c}\text { Spiritual Growth } \\
B\end{array}$} \\
\hline & $\beta$ & B & CI's & $p$ & $\mathbf{R}^{2}$ Change \\
\hline Gender & 0.02 & 0.08 & $-0.17,0.33$ & 0.527 & \\
\hline Ethnicity & -0.07 & -0.32 & $-0.63,-0.01$ & 0.041 & \\
\hline \multirow{2}{*}{ Age } & -0.04 & -0.04 & $-0.11,0.03$ & 0.263 & \\
\hline & & & & 0.106 & 0.01 \\
\hline Presence of Meaning & 0.03 & 0.03 & $-0.05,0.12$ & 0.43 & \\
\hline Self-Control & -0.01 & -0.04 & $-0.22,0.14$ & 0.670 & \\
\hline Rel. Participation & $0.32 *$ & 0.45 & $0.34,0.55$ & 0.000 & \\
\hline Universality & -0.09 & -0.07 & $-0.13,-0.02$ & 0.013 & \\
\hline Optimism & 0.06 & 0.11 & $0.01,0.21$ & 0.039 & \\
\hline Compassion & $0.12 *$ & 0.18 & $0.10,0.26$ & 0.000 & \\
\hline Collaborative Style & $0.26 *$ & 0.43 & $0.32,0.53$ & 0.000 & \\
\hline \multirow[t]{4}{*}{ Quest } & $0.14 *$ & 0.05 & $0.03,0.07$ & 0.000 & \\
\hline & & & & 0.000 & $0.37 *$ \\
\hline & \multicolumn{5}{|c|}{ Spiritual Decline } \\
\hline & $\beta$ & B & CI (B) & $p$ & $R^{2}$ Change \\
\hline Gender & -0.03 & -0.09 & $-0.31,-.13$ & 0.436 & \\
\hline Ethnicity & -0.03 & -0.14 & $-0.42,-.13$ & 0.312 & \\
\hline \multirow[t]{2}{*}{ Age } & -0.03 & -0.02 & $-0.08,-.04$ & 0.467 & \\
\hline & & & & 0.602 & 0.002 \\
\hline Presence of Meaning & $-0.17 *$ & -0.18 & $-0.27,-0.10$ & 0.000 & \\
\hline Self-Control & $-0.15 *$ & -0.40 & $-0.58,-0.23$ & 0.000 & \\
\hline Rel. Participation & $-0.15 *$ & -0.18 & $-0.29,-0.08$ & 0.001 & \\
\hline Universality & -0.10 & -0.07 & $-0.13,-0.01$ & 0.016 & \\
\hline Optimism & -0.09 & -0.10 & $-0.23,-0.03$ & 0.009 & \\
\hline Compassion & 0.08 & 0.10 & $0.02,0.19$ & 0.013 & \\
\hline Collaborative Style & -0.09 & -0.13 & $-0.23,0.02$ & 0.017 & \\
\hline \multirow[t]{2}{*}{ Quest } & $0.22 *$ & 0.07 & $0.05,0.09$ & 0.000 & \\
\hline & & & & 0.000 & $0.22 *$ \\
\hline
\end{tabular}

Notes: All analyses controlled for ethnicity, age, and gender. Sample size $=906 . p<0.005=^{*}$.

As a group, the three demographic variables were significant predictors of only post-traumatic growth, with non-White participants indicating greater growth on this criterion than White participants. The wholeness constructs were significantly tied to self-reported growth and decline among r/s 
strugglers, with modest to moderate power of the wholeness predictors for post-traumatic growth $\left(R^{2}\right.$ change $\left.=0.15\right)$, spiritual growth $\left(R^{2}\right.$ change $\left.=0.37\right)$, and spiritual decline $\left(R^{2}\right.$ change $\left.=0.22\right)$. We turn now to the specific predictors within each regression to report the extent to which each variable contributed uniquely to reports of post-traumatic growth, spiritual growth, and spiritual decline.

With respect to perceptions of post-traumatic growth, higher scores on collaboration with God, quest orientation, religious participation, and compassion were linked to greater post-traumatic growth. Regarding reports of spiritual growth, greater collaboration with God, quest orientation, religious participation, and compassion were uniquely connected to greater spiritual growth.

The criterion of greater self-reported spiritual decline was significantly linked to lower presence of meaning in life, self-control, and religious participation. One of the variables, however, produced an unexpected result. Higher levels of quest orientation were predictive of greater spiritual decline.

\section{Discussion}

This study was designed to help clarify the implications of $\mathrm{r} / \mathrm{s}$ struggles for self-reported growth. According to surveys, many people report struggles-related growth, but correlational research on the links between $\mathrm{r} / \mathrm{s}$ struggles and perceived growth has yielded inconsistent results. To account for these mixed findings, we explored one factor that may determine whether people who are struggling with $\mathrm{r} / \mathrm{s}$ experience growth - the degree to which their orienting system is characterized by wholeness.

Wholeness, as conceptualized by Pargament, Wong, and Exline, has to do with how well people put the bits and pieces of their lives together (Pargament et al. 2016; Pargament et al. forthcoming). To highlight a few of its key qualities, wholeness is a process that involves people in their entirety, including their values, thoughts, feelings, actions, and relationships. No one is fully whole; instead, people vary in their degree of wholeness. In addition, wholeness is not the opposite of brokenness; after all, everyone is wounded to some extent. Wholeness must build upon brokenness. Wholeness consists of several dimensions. In this paper, we focused on four dimensions: purposiveness, breadth and depth, life affirmation, and cohesiveness.

We selected two measures to represent each dimension of wholeness, and then tested whether and the extent to which these eight indicators were tied to three growth-related measures. Because this area of study is still in its very early stages of development, we selected indicators of the dimensions of wholeness on purely conceptual grounds. However, they covered a range of constructs, including both religious and nonreligious domains.

The findings were generally in accord with our expectations. In the correlational analyses, the measures of wholeness were generally associated with the criteria of growth as expected, with two unexpected findings: higher levels of quest were tied to greater spiritual decline, and universality was linked to less post-traumatic growth and spiritual growth, and greater spiritual decline. However, after controlling for the effects of the other wholeness measures in the regression analyses, universality was no longer significantly related to the indices of growth or decline. Regression analyses indicated that, as a group, the four dimensions of wholeness and the eight measures of wholeness were modestly to moderately associated with self-reported post-traumatic growth, spiritual growth, and spiritual decline. Generally, the indicators were tied to growth in expected directions. More specifically, higher levels of collaborative religious coping, the presence of meaning, religious participation, compassion, self-control, and quest were associated with reports of growth on at least one of the three criterion measures.

These findings may help explain the mixed results that have emerged from studies of the links between $\mathrm{r} / \mathrm{s}$ struggles and self-reported growth. Whether growth occurs among people facing $\mathrm{r} / \mathrm{s}$ struggles may depend on the degree of wholeness that characterizes the individual's orienting system. This is the key message to take from this study, one that may also help to integrate the emerging literature on the factors that facilitate the potential of $\mathrm{r} / \mathrm{s}$ struggles for perceived growth (e.g., Desai and Pargament 2015; Exline et al. 2017; Saritoprak et al. 2017; Szcześniak et al. 2020; Wilt et al. 2016, 2019b, 2019c). 
Nevertheless, one puzzling finding emerged that deserves attention. The quest measure was tied to self-reported post-traumatic growth and spiritual growth, as expected, but unexpectedly, to more spiritual decline. The openness to change and willingness to ask questions embedded in quest may be accompanied by both gains and losses. It may be the case that tension and strain are a necessary by-product of trying out new ways of thinking and acting, even if these changes are ultimately beneficial. That is, tension and strain may accompany the willingness to ask questions about cherished values, beliefs, and perspectives so as to potentially discard orienting elements and realize greater truths and purposes. Further study should attempt to replicate this finding.

Although not all of the findings of this study are easy to explain, they do underscore the multi-dimensionality of the growth construct. In this vein, while a positive correlation emerged between spiritual growth and post-traumatic growth $(r=0.59)$, it was not so strong as to indicate that the two measures are identical to each other. It is also interesting that the measures of spiritual growth and decline were only modestly correlated with each other $(r=-0.12)$. This suggests that self-reported growth and decline may co-occur following $\mathrm{r} / \mathrm{s}$ struggles. A survey finding by Desai and Pargament (2015) lends some credence to this possibility. When asked whether they had grown, declined, or both grown and declined through their $\mathrm{r} / \mathrm{s}$ struggles, $29 \%$ of the college student sample indicated that they had both grown and declined. In short, the relationships between some indicators of wholeness and growth appear to be nuanced and complex, varying according to the way growth is understood and measured.

\section{Limitations and Further Research}

There were several limitations to this study. The sample consisted of college students attending universities in the United States. Whether these findings generalize to other populations and non-Western contexts remains to be determined.

The design of the study was cross-sectional. Although perceptions of change are built into the construct of self-reported growth, both the indicators of wholeness and self-reported growth were assessed at the same point in time. Thus, we cannot know whether wholeness leads to growth, growth leads to wholeness, or both processes unfold together over time. Longitudinal studies are needed to unpack the temporality of these possible effects. Moreover, it may take time for the potential benefits of $r / s$ struggles to emerge. Long-term follow-up studies would provide a stronger test of the relationships between wholeness and growth among $\mathrm{r} / \mathrm{s}$ strugglers, as well as the factors that may facilitate these effects.

Future studies should also consider how the construct of wholeness differs from other related constructs, such as personality and positive and negative affect. Wholeness, as defined here, encompasses individual, social, behavioral, cognitive, motivational, affective, and experiential aspects of functioning. Thus, because wholeness can be understood at both personal and social levels, we do not believe that the links between wholeness and growth can be fully explained by personality variables. Moreover, because wholeness is not limited to affect, we do not believe that the associations between wholeness and growth can be fully explained by negative affect. Of course, "the proof is in the pudding," and future studies should consider the linkages between wholeness and other constructs, such as personality and negative affect. Whether wholeness adds unique variance to the prediction of growth after controlling for personality and negative affect would be another worthwhile research question to pursue.

As we have noted, the measures of wholeness and its ingredients were selected solely on conceptual grounds. Even though our indicators represent the most comprehensive assessment of wholeness to date, they do not assess wholeness in its full richness and complexity. For instance, we did not tap into the elements of wisdom and discernment that are an important part of the cohesive dimension of wholeness. Qualitative studies, such as the work of Russo-Netzer (2018) could be valuable in efforts to advance the measurement of wholeness. Factor analytic work is also needed to determine whether these or other ingredients of wholeness form independent factors or are part of a larger 
overarching wholeness dimension. Other studies might consider whether wholeness is accompanied by a greater growth-minded purposiveness that propels higher levels of growth and development. Within-person analytical techniques such as latent profile analysis would also add to variable-centered approaches to the study of wholeness and growth. Nevertheless, we believe that our measures of wholeness represent a promising start. Notably, each of the wholeness measures was significantly correlated with two or more of the three growth-related criterion measures. The items in the measures of wholeness and growth were largely positively phrased with some exceptions (e.g., spiritual decline). As a result, the findings of this study could be biased by an acquiescent response set (McCrae et al. 2001). This limitation could be addressed in future studies by considering the implications of both wholeness and brokenness for growth. Finally, further research should test whether the measures of wholeness moderate the relationships between $\mathrm{r} / \mathrm{s}$ struggles and growth in a broader sample that includes both $\mathrm{r} / \mathrm{s}$ strugglers and non-strugglers.

It is important to acknowledge criticisms that have been made of the self-reported growth construct and measures. Some have argued that perceptions of growth do not correspond to actual changes but are instead psychological defense mechanisms (Maercker and Zoellner 2004), reflections of cultural scripts (Linley and Joseph 2004), or attempts to make meaning of difficult times (Jayawickreme and Blackie 2014). Although research that addresses this topic has not yielded clear-cut findings (e.g., Trevino et al. 2016), several studies have shown some support for the validity of self-reported growth. One set of studies has linked perceptions of post-traumatic growth to actual increases in positive psychological functioning over time (e.g., Park and Fenster 2004; Ransom et al. 2008). Self-reports of growth have also been corroborated by significant others (e.g., Shakespeare-Finch and Enders 2008). And in one study, perceptions of spiritual growth were associated with actual religious and spiritual changes over time (Haugen 2012). Finally, an argument can be made that self-reports of growth are clinically meaningful indications of how people are reconstructing their life story following a time of tension, strain, and conflict.

\section{Implications}

$\mathrm{R} / \mathrm{s}$ struggles have been robustly tied to distress and mental health problems. It should not be surprising, then, that $\mathrm{r} / \mathrm{s}$ struggles are commonplace among people who seek out psychological treatment (Murphy et al. 2016; Rosmarin et al. 2014). However, the findings from this study suggest that $\mathrm{r} / \mathrm{s}$ struggles have implications that go beyond emotional problems. People may perceive growth from their struggles, under the right conditions. Our focus here has been on the individual's degree of wholeness as a significant determinant of self-reported growth among $\mathrm{r} / \mathrm{s}$ strugglers. If growth in the wake of $\mathrm{r} / \mathrm{s}$ struggles does indeed depend in part on wholeness, then there would be value to practical activities designed to foster the ingredients of greater wholeness-purposiveness, breadth and depth, life affirmation, and cohesiveness. Many existing therapies implicitly do just that, including meaning-centered therapies, depth-oriented treatments, positive psychological interventions, and acceptance and commitment therapy. Wholeness is also implicitly addressed in new treatments that attend to r/s struggles (e.g., Dworsky et al. 2013; Harris et al. 2011; Murray-Swank and Pargament 2005; Starnino et al. 2019). We believe that psychological treatments may be enhanced further by more explicit attention to wholeness (i.e., naming wholeness) as an overarching goal for treatment, particularly for people dealing with the tensions, strains, and conflicts that are part of r/s struggles.

Author Contributions: J.J.E. and K.I.P. designed the larger study. A.C.H. and K.I.P. were responsible for the conceptualization and design of this particular study. Data analyses were conducted by A.C.H. with the assistance of J.B.G., J.A.W., J.J.E., and K.I.P. All of the co-authors contributed to data interpretation. The discussion of the findings and their implications was led by A.C.H. and K.I.P. with the assistance of J.B.G., J.A.W., and J.J.E. All authors have read and agreed to the published version of the manuscript.

Funding: This research was supported by grants from the John Templeton Foundation (\#36094, \#59916).

Conflicts of Interest: The authors declare no conflict of interest. 


\section{References}

Abu-Raiya, Hisham, Kenneth I. Pargament, Neal Krause, and Gail Ironson. 2015. Religious coping among diverse religions: Commonalities and divergences. Psychology of Religion and Spirituality 7: 24-33. [CrossRef]

Abu-Raiya, Hisham, Kenneth I. Pargament, Neal Krause, and Gail Ironson. 2015. Robust links between religious/spiritual struggles, psychological distress, and well-being in a national sample of American adults. American Journal of Orthopsychiatry 85: 565-75. [CrossRef] [PubMed]

Abu-Raiya, Hisham, Kenneth I. Pargament, and Neal Krause. 2016. Religion as problem, Religion as solution: Religious buffers of the links between religious/spiritual struggles and well-being/mental health. Quality of Life Research 25: 1265-74. [CrossRef] [PubMed]

Allport, Gordon W. 1950. The Individual and His Religion: A Psychological Interpretation. New York: MacMillan Company.

Baltes, Paul B., and Ursula M. Staudinger. 2000. Wisdom: A metaheuristic (pragmatic) to orchestrate mind and virtue toward excellence. American Psychologist 55: 122. [CrossRef]

Batson, Charles Daniel, and Patricia A. Schoenrade. 1991. Measuring religion as quest: (2) Reliability concerns. Journal for the Scientific Study of Religion 30: 430-47. [CrossRef]

Batson, Charles Daniel, Patricia Schoenrade, and W. Larry Vents. 1993. Religion and the Individual: A Social-Psychological Perspective. New York: Oxford University Press.

Beck, Richard, and Ryan K. Jessup. 2004. The multidimensional nature of quest motivation. Journal of Psychology and Theology 32: 283-94. [CrossRef]

Bussing, Arndt, Andreas Gunther, Klaus Baumann, Eckhard Frick, and Christopher Jacobs. 2013. Spiritual dryness as a measure of a specific spiritual crisis in Catholic priests: Associations with symptoms of burnout and distress. Evidence-Based Complementary and Alternative Medicine 2013: 1-10. [CrossRef]

Calhoun, Lawrence G., Arnie Cann, Richard G. Tedeschi, and Jamie McMillan. 2000. A correlational test of the relationship between posttraumatic growth, religion, and cognitive processing. Journal of Traumatic Stress 13: 521-27. [CrossRef]

Campbell, Joseph. 2008. The Hero with a Thousand Faces. Novato: New World Library.

Chan, Christian S., and Jean E. Rhodes. 2013. Religious coping, posttraumatic stress, psychological distress, and posttraumatic growth among female survivors four years after Hurricane Katrina. Journal of Traumatic Stress 26: 257-65. [CrossRef]

Chang, Edward C., Albert Maydeu-Olivares, and Thomas J. D'Zurilla. 1997. Optimism and pessimism as partially independent constructs: Relationship to positive and negative affectivity and psychological well-being. Personality and Individual Differences 23: 443-40. [CrossRef]

Chittister, Joan D. 2003. Scarred by Struggle, Transformed by Hope. Grand Rapids: William B. Eerdmans.

Cole, Brenda S., Clare M. Hopkins, John Tisak, Jennifer L. Steel, and Brian I. Carr. 2008. Assessing spiritual growth and spiritual decline following a diagnosis of cancer: Reliability and validity of the spiritual transformation scale. Psycho-Oncology: Journal of the Psychological, Social and Behavioral Dimensions of Cancer 17: 112-21. [CrossRef] [PubMed]

Desai, Kavita M., and Kenneth I. Pargament. 2015. Predictors of growth and decline following spiritual struggles. International Journal for the Psychology of Religion 25: 42-56. [CrossRef]

Doehring, Carrie. 2015. The Practice of Pastoral Care: A Postmodern Approach, rev. and exp. ed. Louisville: Westminster John Knox Press.

Dworsky, Carmen K. Oemig, Kenneth I. Pargament, Meryl Reist Gibbel, Carol Ann Faigin, Maria R. Gear Haugen, Kavita M. Desai, Shauna K. Lauricella, Quinten Lynn, and Heidi L. Warner. 2013. Winding road: Preliminary support for a spiritually integrated intervention addressing college students' spiritual struggles. In Research in the Social Scientific Study of Religion. Leiden: Brill, vol. 24, pp. 309-39.

Erikson, Erik H. 1998. The Life Cycle Completed. New York: W. W. Norton.

Exline, Julie J. 2013. Religious and spiritual struggles. In APA Handbook of Psychology, Religion, and Spirituality (Volume 1: Context, Theory, and Research). Edited by Kenneth I. Pargament, Julie J. Exline and James W. Jones. Washington: American Psychological Association, pp. 459-75.

Exline, Julie J., Ann Marie Yali, and William C. Sanderson. 2000. Guilt, discord, and alienation: The role of religious strain in depression and suicidality. Journal of Clinical Psychology 56: 1481-96. [CrossRef] 
Exline, Julie J., Kenneth I. Pargament, Joshua B. Grubbs, and Ann Marie Yali. 2014a. The Religious and Spiritual Struggles Scale: Development and initial validation. Psychology of Religion and Spirituality 6: $208-22$. [CrossRef]

Exline, Julie J., Kenneth I. Pargament, and Todd W. Hall. 2014b. Religious and spiritual issues in college life: Results from three universities. Unpublished raw data.

Exline, Julie J., Todd W. Hall, Kenneth I. Pargament, and Valencia A. Harriott. 2017. Predictors of growth from spiritual struggle among Christian undergraduates: Religious coping and perceptions of helpful action by God are both important. The Journal of Positive Psychology 12: 501-8. [CrossRef]

Fowler, James W. 1981. Stages of Faith: The Psychology of Human Development and the Quest for Meaning. San Francisco: Harper and Row.

Frank, Anne. 2010. The Diary of a Young Girl. London: Everyman's Library.

Frankl, Viktor E. 1959. Man's Search for Meaning. New York: Washington Square Press.

Hall, Deborah, David C. Matz, and Wendy Wood. 2010. Why don't we practice what we preach? A meta-analytic review of religious racism. Personality and Social Psychology Review 14: 126-89. [CrossRef]

Harris, J. Irene, Christopher R. Erbes, Brian E. Engdahl, Paul Thuras, Nichole Murray-Swank, Dixie Grace, Henry Ogden, Raymond H.A. Olson, Ann Marie Winskowski, Russ Bacon, and et al. 2011. The effectiveness of a trauma focused spiritually integrated intervention for veterans exposed to trauma. Journal of Clinical Psychology 67: 425-38. [CrossRef]

Haugen, Maria R. G. 2012. Does Trauma Lead to Religiousness? A Longitudinal Study of the Effects of Traumatic Events on Religiousness and Spirituality during the First Three Years at University. Ph.D. dissertation, Bowling Green State University, Bowling Green, OH, USA.

Hood, Ralph W., Jr., Peter C. Hill, and Bernard Spilka. 2018. The Psychology of Religion: An Empirical Approach, 5th ed. New York: Guilford Press.

Huang, Bu, Amy L. Ai, Catherine M. Lemieux, and Terrence N. Tice. 2011. Modeling the post-9/11 meaning-laden paradox: From deep connection and deep struggle to posttraumatic stress and growth. Archive for the Psychology of Religion 33: 173-204.

Hwang, Jeong Yeon, Thomas Plante, and Katy Lackey. 2008. The development of the Santa Clara brief compassion scale: An abbreviation of Sprecher and Fehr's compassionate love scale. Pastoral Psychology 56: 421-28. [CrossRef]

James, William. 1902. The Varieties of Religious Experience: A Study in Human Nature. New York: Modern Library. Jayawickreme, Eranda, and Laura E. Blackie. 2014. Post-traumatic growth as positive personality change: Evidence, controversies and future directions. European Journal of Personality 28: 312-31. [CrossRef]

King, Stephen D. W., George Fitchett, Patricia E. Murphy, Kenneth I. Pargament, David A. Harrison, and Elizabeth T. Loggers. 2017. Determining best methods for screening for religious/spiritual distress. Supportive Care in Cancer 25: 471-79. [CrossRef] [PubMed]

Kitchens, Michael B. 2015. Thinking about God causes internal reflection in believers and unbelievers. Self and Identity 14: 724-47. [CrossRef]

Kurtz, Ernst, and Katherine Ketcham. 1992. The Spirituality of Imperfection: Storytelling and the Search for Meaning. New York: Bantam Books.

Licht, Mark. H. 1995. Multiple regression and correlation. In Reading and Understanding Multivariate Statistics. Edited by Laurence G. Grimm and Paul R. Yarnold. Washington: American Psychological Association, pp. 19-64.

Linley, P. Alex, and Stephen Joseph. 2004. Positive change following trauma and adversity: A review. Journal of Traumatic Stress 17: 11-21. [CrossRef] [PubMed]

Maercker, Andreas, and Tanja Zoellner. 2004. The Janus face of self-perceived growth: Toward a two-component model of posttraumatic growth. Psychological Inquiry 15: 41-48.

McCrae, Robert R., Jeffrey H. Herbst, and Paul T. Costa Jr. 2001. Effects of acquiescence on personality factor structures. In Personality and Temperament: Genetics, Evolution, and Structure. Edited by Rainer Riemann, Fritz Ostendorf and Frank M. Spinath. Berlin: Pabst Science Publishers, pp. 217-31.

Morgan, Jonathan, and Steven J. Sandage. 2016. A developmental model of interreligious competence. Archive for the Psychology of Religion 38: 129-58. [CrossRef] 
Murphy, Patricia E., George Fitchett, and Erin E. Emery-Tiburcio. 2016. Religious and spiritual struggle: Prevalence and correlates among older adults with depression in the BRIGHTEN Program. Mental Health, Religion and Culture 19: 713-21. [CrossRef]

Murray-Swank, Nichole A., and Kenneth I. Pargament. 2005. God, where are you? Evaluating a spiritually-integrated intervention for sexual abuse. Mental Health, Religion and Culture 8: 191-203. [CrossRef]

New World Encyclopedia. 2008. Holy. In New World Encyclopedia. Available online: http://www. newworldencyclopedia.org/entry/Holy (accessed on 1 July 2018).

Palmer, Parker J. 2004. A Hidden Wholeness: The Journey toward an Undivided Life. New York: Jossey-Bass.

Pargament, Kenneth I. 2007. Spiritually Integrated Psychotherapy: Understanding and Addressing the Sacred. New York: Guilford Press.

Pargament, Kenneth I., and Julie J. Exline. Forthcoming a. Religious and spiritual struggles and mental health: Implications for clinical practice. In Spirituality and Mental Health Across Cultures. Edited by Alexander Moreira-Almeida and Bruno Paz Mosqueiro. Oxford: Oxford University Press.

Pargament, Kenneth I., and Julie J. Exline. Forthcoming b. Shaken to the Core: Spiritual Struggles in Research and Clinical Practice. New York: Guilford Press.

Pargament, Kenneth I., Joseph Kennell, William Hathaway, Nancy Grevengoed, Jon Newman, and Wendy Jones. 1988. Religion and the problem-solving process: Three styles of coping. Journal for the Scientific Study of Religion 27: 90-104. [CrossRef]

Pargament, Kenneth I., Bruce W. Smith, Harold G. Koenig, and Lisa Perez. 1998. Patterns of positive and negative religious coping with major life stressors. Journal for the Scientific Study of Religion 37: 710-24. [CrossRef]

Pargament, Kenneth. I., Nichole Murray-Swank, Gina Magyar, and Gene G. Ano. 2005. Spiritual struggle: A phenomenon of interest to psychology and religion. In Judeo-Christian Perspectives on Psychology: Human Nature, Motivation, and Change. Edited by William R. Miller and Harold H. Delaney. Washington: American Psychological Association, pp. 245-68.

Pargament, Kenneth I., Serena Wong, and Julie J. Exline. 2016. Wholeness and holiness: The spiritual dimension of eudaimonics. In Handbook of Eudaimonic Well-Being. New York: Springer Press, pp. 379-94.

Pargament, Kenneth. I., Serena Wong, and Julie J. Exline. forthcoming. The holiness of wholeness: Religious contributions to human flourishing. In Oxford Handbook of Humanities and Human Flourishing. Edited by James O. Pawelski and Louis Tay. New York: Oxford Press.

Park, Crystal L., and Juliane R. Fenster. 2004. Stress-related growth: Predictors of occurrence and correlates with psychological adjustment. Journal of Social and Clinical Psychology 23: 195-215. [CrossRef]

Park, Crystal L., Philip H. Smith, Sharon Y. Lee, Carolyn M. Mazure, Sherry A. McKee, and Rani Hoff. 2017. Positive and negative religious/spiritual coping and combat exposure as predictors of posttraumatic stress and perceived growth in Iraq and Afghanistan veterans. Psychology of Religion and Spirituality 9: 13-20. [CrossRef]

Piedmont, Ralph L. 2020. Assessment of Religious and Spiritual Sentiments (ASPIRES) Scale, Technical Manual, 3rd ed. Timonium: Piedmont.

Pomerleau, Julie M., Kenneth I. Pargament, and Annette Mahoney. 2017. Seeing life through a sacred lens: The spiritual dimension of meaning. In Clinical Perspectives on Meaning: Positive and Existential Psychotherapy. Edited by Alexander Batthyany, Pninit Russo-Netzer and Stefan E. Schulenberg. New York: Springer Press, pp. 37-57.

Prati, Gabriele, and Luca Pietrantoni. 2009. Optimism, social support, and coping strategies as factors contributing to posttraumatic growth: A meta-analysis. Journal of Loss and Trauma 14: 364-88. [CrossRef]

Ransom, Sean, Kennon M. Sheldon, and Paul B. Jacobsen. 2008. Actual change and inaccurate recall contribute to posttraumatic growth following radiotherapy. Journal of Consulting and Clinical Psychology 76: 811-19. [CrossRef] [PubMed]

Rockenbach, Alyssa Bryant, Coretta Roseboro Walker, and Jordan Luzader. 2012. A phenomenological analysis of college students' spiritual struggles. Journal of College Student Development 53: 55-75. [CrossRef]

Rosmarin, David H., Mary C. Malloy, and Brent P. Forester. 2014. Spiritual struggle and affective symptoms among geriatric mood disordered patients. International Journal of Geriatric Psychiatry 29: 653-60. [CrossRef]

Russo-Netzer, Pninit. 2018. Healing the divide through wholeness: Holding on to what makes us human. International Journal of Existential Positive Psychology 7: 17. Available online: http://journal. existentialpsychology.org/index.php/ExPsy/article/view/226 (accessed on 24 March 2018). 
Saritoprak, Seyma N., Julie J. Exline, Todd J. Hall, and Kenneth I. Pargament. 2017. Does God use struggles to transform us? Paper presented at Mid-year Conference on Psychology, Religion and Spirituality, Chattanooga, TN, USA, 7-8 April 2017.

Scheier, Michael F., and Charles S. Carver. 1992. Effects of optimism on psychological and physical well-being: Theoretical overview and empirical update. Cognitive Therapy and Research 16: 201-28. [CrossRef]

Scheier, Michael F., Charles S. Carver, and Michael W. Bridges. 1994. Distinguishing optimism from neuroticism (and trait anxiety, self-mastery, and self-esteem): A reevaluation of the Life Orientation Test. Journal of Personality and Social Psychology 6: 1063-78. [CrossRef]

Sedlar, Aaron E., Nick Stauner, Kenneth I. Pargament, Julie J. Exline, Josh B. Grubbs, and David E. Bradley. 2018. Spiritual struggles among atheists: Links to psychological distress and well-being. Religions 9: 242. [CrossRef]

Shakespeare-Finch, Jane, and Tracey Enders. 2008. Corroborating evidence of posttraumatic growth. Journal of Traumatic Stress 21: 421-24. [CrossRef] [PubMed]

Starnino, Vincent R., Clyde T. Angel, John E. Sullivan, Donna L. Lazarick, Licci D. Jaimes, John P. Cocco, and Louanne W. Davis. 2019. Preliminary report on a spiritually-based PTSD intervention for military veterans. Community Mental Health Journal 55: 1114-19. [CrossRef] [PubMed]

Stauner, Nick, Julie J. Exline, Kenneth I. Pargament, Joshua A. Wilt, and Joshua B. Grubbs. 2019. Stressful life events and religiousness predict struggles about religion and spirituality. Psychology of Religion and Spirituality 11: 291-96. [CrossRef]

Steger, Michael F., and Patricia Frazier. 2005. Meaning in life: One link in the chain from religiousness to well-being. Journal of Counseling Psychology 52: 574-82. [CrossRef]

Steger, Michael F., Patricia Frazier, Shigehiro Oishi, and Matthew Kaler. 2006. The meaning in life questionnaire: Assessing the presence of and search for meaning in life. Journal of Counseling Psychology 53: 80. [CrossRef]

Szcześniak, Małgorzata, Zdzisław Kroplewski, and Roman Szałachowski. 2020. The mediating effect of coping strategies on religious/spiritual struggles and life satisfaction. Religions 11: 195. [CrossRef]

Tangney, June P., Roy F. Baumeister, and Angie Luzio Boone. 2004. High self-control predicts good adjustment, less pathology, better grades, and interpersonal success. Journal of Personality 72: 271-324. [CrossRef]

Tarakeshwar, Nalini, and Kenneth I. Pargament. 2001. Religious coping in families of children with autism. Focus on Autism and Other Developmental Disabilities 16: 247-60. [CrossRef]

Tedeschi, Richard G., and Lawrence G. Calhoun. 1996. The Posttraumatic Growth Inventory: Measuring the positive legacy of trauma. Journal of Traumatic Stress 9: 455-71. [CrossRef]

Teng, Ellen J., Melinda A. Stanley, Julie J. Exline, and Kenneth I. Pargament. 2016. Frequency of reports of religious and spiritual growth following religious and spiritual struggles. Unpublished data.

Trevino, Kelly M., Aanand D. Naik, and Jennifer Moye. 2016. Perceived and actual change in religion/spirituality in cancer survivors: Longitudinal relationships with distress and perceived growth. Psychology of Religion and Spirituality 8: 195-205. [CrossRef] [PubMed]

Viser, Anja, Nicoline Uwland-Sikkema, Gerber Westerhof, and Bert Garssen. 2020. The role of the spiritual meaning system in coping with cancer. Religions 11: 49. [CrossRef]

Vishkin, Allon, Yochanan E. Bigman, Roni Porat, Nevin Solak, Eran Halperin, and Maya Tamir. 2016. God rest our hearts: Religiosity and cognitive reappraisal. Emotion 16: 252-62. [CrossRef] [PubMed]

Wilt, Joshua A., Joshua B. Grubbs, Julie J. Exline, and Kenneth I. Pargament. 2016. Personality, religious and spiritual struggles, and well-being. Psychology of Religion and Spirituality 8: 341-51. [CrossRef]

Wilt, Joshua A., Julie J. Exline, Matthew J. Lindberg, Crystal L. Park, and Kenneth I. Pargament. 2017a. Theological beliefs about suffering and interactions with the divine. Psychology of Religion and Spirituality 9: 137-47. [CrossRef]

Wilt, Joshua A., Todd W. Hall, Kenneth I. Pargament, and Julie J. Exline. 2017b. Trajectories of religious/spiritual struggles between years 1 and 2 of college: The predictive role of religious belief salience. International Journal of the Psychology of Religion 27: 172-87. [CrossRef]

Wilt, Joshua A., Kenneth I. Pargament, and Julie J. Exline. 2019a. The transformative power of the sacred: Social, personality, and religious/spiritual antecedents and consequents of sacred moments during a religious/spiritual struggle. Psychology of Religion and Spirituality 11: 233-46. [CrossRef] 
Wilt, Joshua A., Kenneth I. Pargament, Julie J. Exline, Terri L. Barrera, and Ellen J. Teng. 2019b. Spiritual transformation among veterans in response to a religious/spiritual struggle. Psychology of Religion and Spirituality 11: 266-77. [CrossRef]

Wilt, Joshua A., Nick Stauner, Valencia A. Harriott, Julie J. Exline, and Kenneth I. Pargament. 2019c. Partnering with God: Religious coping and perceptions of divine intervention predict spiritual transformation in response to religious- spiritual struggle. Psychology of Religion and Spirituality 11: 278-90. [CrossRef]

Zarzycka, Beata, and Małgorzata M. Puchalska-Wasyl. 2019. Can religious and spiritual struggle enhance well-being? Exploring the mediating effects of internal dialogues. Journal of Religion and Health, 1-16. [CrossRef]

Zeligman, Melissa, Aaron R. Majuta, and Laura R. Shannonhouse. 2020. Posttraumatic growth in prolonged drought survivors in Botswana: The role of social support and religious coping. Traumatology. in press. [CrossRef]

(C) 2020 by the authors. Licensee MDPI, Basel, Switzerland. This article is an open access article distributed under the terms and conditions of the Creative Commons Attribution (CC BY) license (http://creativecommons.org/licenses/by/4.0/). 